\title{
Coping Style and Early Life Vocalizations in the Common Marmoset (Callithrix jacchus)
}

\author{
Sergio Díaz ${ }^{1}$ - Susana Sánchez ${ }^{2}$ - Ana Fidalgo ${ }^{2}$
}

Received: 9 November 2019 / Accepted: 20 March 2020 / Published online: 20 May 2020

(C) The Author(s) 2020

\begin{abstract}
Coping styles describe behavioral differences during stressful or challenging situations. Coping styles are stable over time but little is known about early life manifestation and development of these behavioral differences. We aimed to investigate if differences in the way marmosets produce vocalizations at an early age are related to their coping style in the future. We studied 14 common marmosets (Callithrix jacchus) from three social groups housed at the marmoset colony at Universidad Autónoma de Madrid. We recorded the vocalizations of each marmoset in isolation at 15-17 days of age, analyzing latency to vocalize and calling rate of phee and tsik calls. To measure coping style, we introduced a novel stimulus to the group cages when infants were 3 months old and recorded exploration, headcocking, and approaches to the stimulus. The results showed negative relationships between the latency of phee call (a long-range contact call) at 15-17 days and frequency of exploration and approach to the novel stimulus at 3 months, although both correlations fall above the cut-off points for the false discovery rate. Marmosets that gave long-range calls sooner at 15-17 days of age also showed more exploratory behaviors at 3 months. The results also showed group differences in exploration at 3 months, and twins were more similar to each other than to other infants in the sample. There were no group differences in early vocalizations and no sex differences in any variable. These findings suggest that coping style is stable from as early as 15-17 days after birth and suggest that the group can influence exploration in marmosets.
\end{abstract}

Keywords Common marmoset $\cdot$ Coping styles $\cdot$ Exploration $\cdot$ Vocalizations

Handling Editor: Joanna M. Setchell

Sergio Díaz

s.gonzalezdiaz@chester.ac.uk

1 University of Chester, Chester, Cheshire, UK

2 Universidad Autónoma de Madrid, Madrid, Spain 


\section{Introduction}

Coping styles describe behavioral differences during stressful or challenging situations (Carere et al. 2010; Koolhaas et al. 1999). Behavioral differences have been studied from a variety of approaches and are often included in the broader field of animal personality, which includes the study of any individual difference that is stable across time and contexts (Gosling 2001, 2008; Gosling and John 1999). Other terms used to refer to similar concepts are behavioral syndromes, which is often used in ecological (Sih et al. 2004) and temperament (Clarke and Boinski 1995) studies, more commonly used in studies of primate behavior. However, little is known about when these differences start to manifest and if they are stable from an early age.

The paradigm of coping styles emphasizes the study of differences in response to environmental or social challenges, which makes it an ideal approach in laboratory contexts where behavior can be studied in a controlled environment. Coping styles were initially studied in mice and rats in terms of motor behaviors related to the exploration of a new environment or stimulus (Drent et al. 2003; Koolhaas et al. 2010). Typically, proactive animals respond to stress with a strong sympathetic activation and display more risk-prone behaviors such as aggression and exploration while reactive animals respond to stress with a strong physiological response, characterized by high plasma corticosterone levels and risk-averse behaviors like immobility (Koolhaas et al.1999). A fundamental characteristic of the proactive/reactive axis (Carere et al. 2010; Carere and Locurto 2011) is thus the degree of risk-avoidance behaviors.

Research on primate behavior has used the proactive/reactive axis to study coping strategies during challenging situations. For example, a study that investigated individual differences in stress-related behaviors in captive capuchin monkeys (Sapajus spp.) found two dimensions of behavior consistent with proactive and reactive differences between individuals (Ferreira et al. 2016). Studies of rhesus macaques (Macaca mulatta) showed that anxiety-related behaviors during maternal deprivation at an early age can influence behavior during isolation periods during adulthood (Suomi 1997). Adult macaques housed in isolation display similar behavior to their responses to maternal separation in infancy (Hennessy et al. 2014). This consistency throughout life is also observed in cortisol production, as infant macaques that had higher cortisol production when exposed to a novel stressor also showed higher cortisol values during group formation in adulthood (Linden et al. 2018). Similarly, tufted-ear marmosets (Callithrix geoffroyi) show stable individual differences in phee calling when isolated at 6 and 12 mo of age (Taylor et al. 2014). Interestingly, while most research has investigated these differences in behavior at the individual level, they can also be present between groups. Chimpanzees (Pan troglodytes) show group similarities in social behaviors both in captivity (Koski 2011) and in the wild (Cronin et al. 2014), suggesting that exterior factors such as the social group can affect the expression of individual differences.

The common marmoset (Callithrix jacchus) is a highly social species that lives in cohesive groups, often with one breeding pair of adults (Garber et al. 2016; Schiel and Souto 2017) and has a highly cooperative breeding system where both parents, and other members of the group, take care of the infants (Saito 2015). Research on behavioral differences in common marmosets has often combined the use of 
questionnaires and behavioral observations (Iwanicki and Lehman 2015), and has highlighted the importance of prosocial behavior, suggesting that the evolution of personality in marmosets is highly influenced by their social structure and cooperative breeding (Koski et al. 2017). However, some studies have also used behavioral tests to explore individual differences in challenging situations (Koski and Burkart 2015; Šlipogor et al. 2016). For example, a study using exploration and predation conditions found that marmosets showed exploration tendencies similar to those of other members of their group when tested together, but these similarities were not present when they were tested individually, suggesting that marmosets modify their behavior to coordinate their exploration with others (Koski and Burkart 2015). Although the authors suggest that this might be due to the influence of particular individuals, they also draw attention to the need to examine longitudinal data on developmental changes in coping styles (Koski and Burkart 2015). A similar study found that individual differences in exploration are consistent over time in adult marmosets, but also reports differences in exploration between groups (Šlipogor et al. 2016). Both studies suggest that similarities between group members in new situations facilitate cooperation in social species.

Vocal communication plays an important role in marmoset groups, particularly during parental care (Zahed et al. 2008). The reproductive male and reproductive female of the group respond equally to offspring vocalizations, and these responses were significantly stronger when infants were directly dependent on parental care, 3 weeks after birth, than when infants were mostly independent, 4 months after birth (Sánchez et al. 2014). Vocalizations can be used as indicators of coping style, and individuals from different groups adopt different stress-confronting strategies when exposed to several "predator" stimuli, consisting of different frog and snake models (Clara et al. 2008). The authors of this study proposed that mobbing vocalizations, known as tsiks, function as proactive responses to a threatening stimulus, and thus can be considered a coping mechanism (Clara et al. 2008). The authors also suggested that differences between groups can be explained by social learning, with younger members of the group learned this coping style from their parents (Clara et al. 2008). Tsik calls are also associated with a reduction in the concentration of cortisol in adult common marmosets (Clara et al. 2008; Cross and Rogers 2006). Infants can produce tsik calls as young as 3 weeks of age (Pistorio et al. 2006) in response to distressing or unexpected stimuli, although they might not produce them in the presence of predators (Becerra and Souto 2008).

Another important vocalization, the phee call, has been observed when an individual is separated from their group (Norcross and Newman 1999; Yamaguchi et al. 2010) and might play a central role in long distance contact between groups (Bezerra and Souto 2008). Phee calls are not associated with stress inducing stimuli (Kato et al. 2014) but contain relevant information about the identity of the sender. Phee calls are used in turn-taking vocal social interactions or antiphonal calling (Agamaite et al. 2015; Miller et al. 2010). Infants <3 weeks of age produce phee calls (Pistorio et al. 2006). Although infants produce these calls in response to social or environmental factors, spontaneous vocalization is more common in younger infants, and decreases as they mature during the first 25 weeks (Pistorio et al. 2006). While phee has not been used, to our knowledge, to investigate coping style in the common marmoset, its use to communicate with others when an individual is in isolation make it a potentially relevant vocalization. 
Although coping style appears to be consistent over time in adult common marmosets (Šlipogor et al. 2016), little is known about early development of individual coping styles. We investigate early infant vocalizations of common marmosets at 15-17 days of age in an isolation context and 3 months later their exploring behavior with a new stimulus inside the familiar group. Our hypothesis is that the proactive/reactive styles exist in early life and can be expressed through vocalizations at 15-17 days of age and through motor behaviors at 3 months of age. We predicted that marmosets that vocalized more often and sooner during an isolation test at 15-17 days of age would explore sooner and display more exploratory behaviors when a new stimulus is introduced to their cage at 3 months of age. Additionally, because there is clear evidence of group differences in exploratory behaviors (Koski and Burkart 2015; Šlipogor et al. 2016), boldness behaviors (Koski and Burkart 2015), and mobbing vocalizations (Clara et al. 2008), we investigated differences between vocalizations and exploratory behavior in infants of different groups. Finally, we explored differences in vocalizations and exploratory behavior between the sexes and twins to investigate other possible sources of coping style variation.

\section{Methods}

\section{Subjects and Housing}

We tested 14 common marmosets, 8 males and 6 females forming 7 pairs of twins, in the colony at Universidad Autónoma de Madrid (UAM), Spain. The marmosets were from three social groups, each comprising a reproductive pair and their offspring (Table I). All three groups were housed in independent cages with both outdoor cages (groups A and B: $9.87 \mathrm{~m} \times 4.35 \mathrm{~m} \times 3.28 \mathrm{~m}$; group C: $2.87 \mathrm{~m} \times 2.51 \mathrm{~m} \times 3 \mathrm{~m}$ ) and indoor housing (groups A and B: $2.23 \mathrm{~m} \times 1.59 \mathrm{~m} \times 2.22 \mathrm{~m}$; group C: $1.44 \mathrm{~m} \times 1.44 \mathrm{~m}$ $\times 2.40 \mathrm{~m}$ ). Indoor cages had a constant temperature of $26^{\circ} \mathrm{C}$ and a controlled $12-\mathrm{h}$ light-darkness cycle. All animals were fed twice a day; the first meal was available at 07:30 $\mathrm{h}$ and consisted of porridge made with yogurt, banana puree, wheat germ oil, and added minerals and vitamins, including vitamin $\mathrm{D}$. The second meal was available at 13:00 $\mathrm{h}$ and consisted of a mixture of fruits, nuts, vegetables, and eggs, plus a daily enrichment food of mealworms ( 2 days a week), sunflower seeds ( 2 days a week), and acacia gum (3 days a week). Water was available ad libitum. Each cage had several branches and ropes that served as enrichment (Sánchez et al. 2005).

\section{Data Collection}

We recorded the vocalizations of 15- and 17-day-old marmosets in an isolation test. No infant was removed from the group until it was old enough to thermoregulate. We separated infants from their natal group visually, olfactorily, and acoustically. One researcher handled the infants, placing them on a soft, warm cotton cloth in a Styrofoam box. The researcher moved the infants to an adjoining room, opened the box, and recorded all the vocalizations infants produced for $5 \mathrm{~min}$, using a digital voice recorder. Then, we weighed the infants, collected their scents as urogenital rubs for another study, and placed them back in their groups after no more than $10 \mathrm{~min}$ of separation. 
Table I Study subjects for a study of coping style and early life vocalizations in the common marmoset

\begin{tabular}{llll}
\hline Name & Sex & Group & Group size (excluding infants) \\
\hline California & M & A1 & 2 \\
Copito & M & A1 & 2 \\
Cheetah & F & A2 & 4 \\
Cookie & F & A2 & 4 \\
Whiski & M & B1 & 4 \\
Widette & F & B1 & 4 \\
Washington & F & B2 & 6 \\
Wisconsin & F & B2 & 6 \\
Candy & F & C1 & 4 \\
Cotton & M & C1 & 4 \\
Chip & M & C2 & 6 \\
Chop & M & C2 & 6 \\
Conan & M & C3 & 8 \\
Craken & M & C3 & 8 \\
\hline
\end{tabular}

We analyzed the acoustic data using SASLab Lite software. We recorded the rate of phee and tsik vocalizations, according to published descriptions and spectrograms (Bezerra and Souto 2008; Table II). We measured the latency to the first phee and tsik calls in seconds from the moment the Styrofoam box was opened.

We conducted the exploration test in each group inside the indoor cage. We exposed all group members to the novel stimulus but focused our behavioral observations on the infants. We conducted this test when infants were 3 months old and had sufficient motor capacity to move and jump on their own. We used a transparent closed box measuring $19.5 \mathrm{~cm} \times 10.0 \mathrm{~cm} \times 14.5 \mathrm{~cm}$ containing two live turtles as the novel stimulus. We put the box with the turtles on a $120 \mathrm{~cm} \times 25 \mathrm{~cm} \times 33 \mathrm{~cm}$ platform that was part of the cage furniture and in a central position. The closest branches had a horizontal position and a similar placement in all groups, maintaining a minimum distance of $20 \mathrm{~cm}$ to the

Table II Ethogram for a study of coping style and early life vocalizations in the common marmoset

\begin{tabular}{lllc}
\hline Behavior & Definition & Reference \\
\hline $\begin{array}{c}\text { Exploration } \\
\text { behaviors }\end{array}$ & Proximity & $\begin{array}{c}\text { Infants approached and stood on the platform or the } \\
\text { stimulus } \\
\text { Visual exploration behavior consisting of lateral head } \\
\text { movements }\end{array}$ & $\begin{array}{c}\text { Kaplan and } \\
\text { Rogers (2006) }\end{array}$ \\
& Exploration & $\begin{array}{c}\text { Manipulatory behaviors such as touching, biting, licking, } \\
\text { or sniffing the stimulus }\end{array}$ & $\begin{array}{c}\text { Arruda } \text { et al } \\
\text { (1986) }\end{array}$ \\
& Pocalizations & $\begin{array}{c}\text { Long, loud call generally used to make contact with } \\
\text { conspecifics }\end{array}$ & $\begin{array}{c}\text { Bezerra and } \\
\text { Souto (2008) }\end{array}$ \\
& & $\begin{array}{c}\text { Short call often uttered in series, used by infants in } \\
\text { contexts of distress }\end{array}$ & $\begin{array}{c}\text { Bezerra and } \\
\text { Souto (2008) }\end{array}$ \\
\hline
\end{tabular}


platform. Visual exploration could take place from anywhere in the cage, but the marmosets had to jump onto the platform to explore the novel stimulus using touch, oral manipulation, and olfaction. We collected data when infants approached the platform on their own; there was no instance of an infant being transported to the platform by an adult. The test lasted $20 \mathrm{~min}$, after which we moved the box with the turtles out of the cage and away. Two expert observers with a minimum of 1 year of experience working with the animals collected data. We calculated interrater reliability for $10 \%$ of the observation time, obtaining a Kappa Index of $\kappa=0.853$. Each observer continuously recorded the frequency of approach (how many times the infant approached the stimuli), the frequency and nature of exploration (tactile, orally or olfactory), and the frequency of headcocking (lateral movement with the head while staring at the object, visual exploration) to the novel stimulus (Table II). We measured the latency of approach (how long it took the infant to approach the stimulus for the first time) and exploration (how long it took the infant to explore the stimulus) in seconds. Data collection was not blind, and we collected data with the software ABC Logbook for iPad. We began data collection in October 2012 and finished in February 2014. We conducted all tests between 10:00 $\mathrm{h}$ and 13:00 $\mathrm{h}$.

\section{Statistical Analysis}

We used nonparametric statistics because only the latency to phee call met the assumption of normality (based on the Shapiro-Wilks normality test as well as inspection of measures of skewness and kurtosis). We used Spearman correlations to test the relationship between vocalizations during the isolation test and exploration behaviors during the exploration test. Correlations were one-tailed using an $\alpha$ level of 0.05 . We report the exact $P$-values of the tests, confidence intervals, and effect sizes (Nakagawa 2004), and control for the false discovery rate to highlight when a result has a chance of being a false positive (García 2003; McDonald 2014). We tested for group differences using Kruskal-Wallis test and Mann-Whitney $U$ tests with Bonferroni's test correction for pairwise comparisons. We explored sex differences using Mann-Whitney $U$ tests. We used intraclass correlations (McGraw and Wong 1996) to evaluate whether twins responded similarly in the exploration test. We performed statistical analyses in SPSS 19.0.

Ethical Note Housing conditions, exploration testing, and isolation testing met with protocols approved by the appropriate institutional animal care committee (Research Ethic Committee: CEI-UAM 31-732; PSI2012-30744). The authors declare that they have no conflic of interest.

Data Availability The datasets used and analyzed during the current study are available from the corresponding author on reasonable request.

\section{Results}

Relationships Between Vocalizations and Exploration Behaviors 
We found no significant relationships between the rate of phee calls and all exploration behaviors (Table III). The latency to the first phee call in the isolation test was significantly negatively correlated with the frequency of approach (Table IV, Fig. 1) and with the frequency of exploration (Table IV, Fig. 2) during the exploration test. However, the $P$ value of the correlation between latency of phee and frequency of approach was above the cut-off point when correcting for the false discovery rate $(P=0.005)$. The $P$ value between latency of phee and frequency of exploration was also above the cut-off point when correcting for the false discovery rate $(P=0.0025)$. Correlations between rate of calling for tsik and exploration (Table V) and between latency of tsik and exploration (Table VI) were not significant.-

\section{Group Differences}

There was no statistical difference between the three groups in the latency to the first phee call $(H(2)=4.807, P=0.09)$ or tsik $(H(2)=1.642, P=0.440)$ or in the rate of phee $(H(2)=1.297, P=0.523)$ or tsik calls $(H(2)=0.096, P=0.953)$. However, we found differences in the latency of approach to the platform between infants from different groups $(H(2)=8.936, P=0.011)$. Pairwise tests showed that infants from group A $(M E D=900, S D=30)$ took longer to approach the platform than infants from group $\mathrm{C}(M E D=117.5, S D=262.3)(U=0, \mathrm{P}=0.01)$, although there was no difference in latency of access between groups $\mathrm{A}$ and $\mathrm{B}(M E D=675, S D=259.8)$ $(U=5, P=0.486)$ or between groups $\mathrm{B}$ and $\mathrm{C}(U=2, P=0.038)$. We also found differences in the latency of exploratory behavior $(H(2)=10,358, P=0.006)$ and infants from group A $(M E D=900, S D=115)$ took longer to explore the novel stimulus than infants from group $\mathrm{C}(M E D=55, S D=85.1)(U=0, P=0.01)$ and infants from group $\mathrm{B}(M E D=670, S D=277.6)$ took longer than infants from group $\mathrm{C}(U=0, P=$ $0.01)$, but we found no significant difference between groups $\mathrm{A}$ and $\mathrm{B}(U=5, P=$ 0.486).

We also found difference in the frequency of headcocking among infants from the three groups $(H(2)=7.231, P=0.028)$. Post hoc tests showed that infants from group $\mathrm{A}(M E D=0, S D=1)$ showed less headcocking than infants from group $\mathrm{C}(M E D=8, S D=5.8)(U=0, P=0.01)$, but we found no significant difference between groups $\mathrm{A}$ and $\mathrm{B}(M E D=3, S D=4.5)(U=5, P=0.486)$ or between groups $\mathrm{B}$ and $\mathrm{C}(U=5, P=0.171)$. We found differences in the

Table III Results of Spearman's correlation tests of the relationship between the rate of phee vocalizations in an isolation test and exploration behaviors in an exploration test for common marmosets at the Universidad Autónoma de Madrid colony, Spain (2012-2014)

\begin{tabular}{llllll}
\hline & $\begin{array}{l}\text { Frequency } \\
\text { of headcocking }\end{array}$ & $\begin{array}{l}\text { Frequency } \\
\text { of approach }\end{array}$ & $\begin{array}{l}\text { Frequency } \\
\text { of exploration }\end{array}$ & $\begin{array}{l}\text { Latency } \\
\text { of approach }\end{array}$ & $\begin{array}{l}\text { Latency } \\
\text { of exploration }\end{array}$ \\
\hline$R$ & -0.119 & -0.107 & 0.108 & -0.017 & -0.053 \\
$P$ & 0.343 & 0.358 & 0.357 & 0.477 & 0.429 \\
Lower CI & -0.577 & -0.763 & -0.626 & -0.603 & -0.570 \\
Upper CI & 0.383 & 0.487 & 0.642 & 0.639 & 0.505 \\
\hline
\end{tabular}


Table IV Results of Spearman's correlation tests of the relationship between the latency to the first phee call in an isolation test and exploration behaviors in an exploration test for common marmosets at the Universidad Autónoma de Madrid colony, Spain (2012-2014)

\begin{tabular}{llllll}
\hline & $\begin{array}{l}\text { Frequency of } \\
\text { headcocking }\end{array}$ & $\begin{array}{l}\text { Frequency } \\
\text { of approach }\end{array}$ & $\begin{array}{l}\text { Frequency } \\
\text { of exploration }\end{array}$ & $\begin{array}{l}\text { Latency of } \\
\text { approach }\end{array}$ & $\begin{array}{l}\text { Latency of } \\
\text { exploration }\end{array}$ \\
\hline$R$ & -0.444 & $-0.614^{*}$ & $-0.696^{* *}$ & 0.378 & 0.428 \\
$P$ & 0.056 & 0.009 & 0.003 & 0.092 & 0.063 \\
Lower CI & -0.893 & -0.907 & -0.943 & -0.309 & -0.214 \\
Upper CI & 0.157 & -0.094 & -0.220 & 0.888 & 0.926 \\
\hline
\end{tabular}

*Indicates correlations significant at $P<0.05$. **Indicates correlations significant at $P<0.01$.

frequency of exploration $(H=6.764, P=0.034)$ : infants from group A $(M E D=0$, $S D=0)$ showed fewer exploratory behaviors than infants from group C $(M E D=1$, $S D=16.8)(U=0, P=0.01)$, but we found no significant difference between group A and group $\mathrm{B}(M E D=5, S D=6.8)(U=4, P=0.343)$ or between group B and group $\mathrm{C}(U=8, P=0.476)$. We found no significant statistical differences between groups for the frequency of approach $(H(2)=4.305, P=0.116)$.

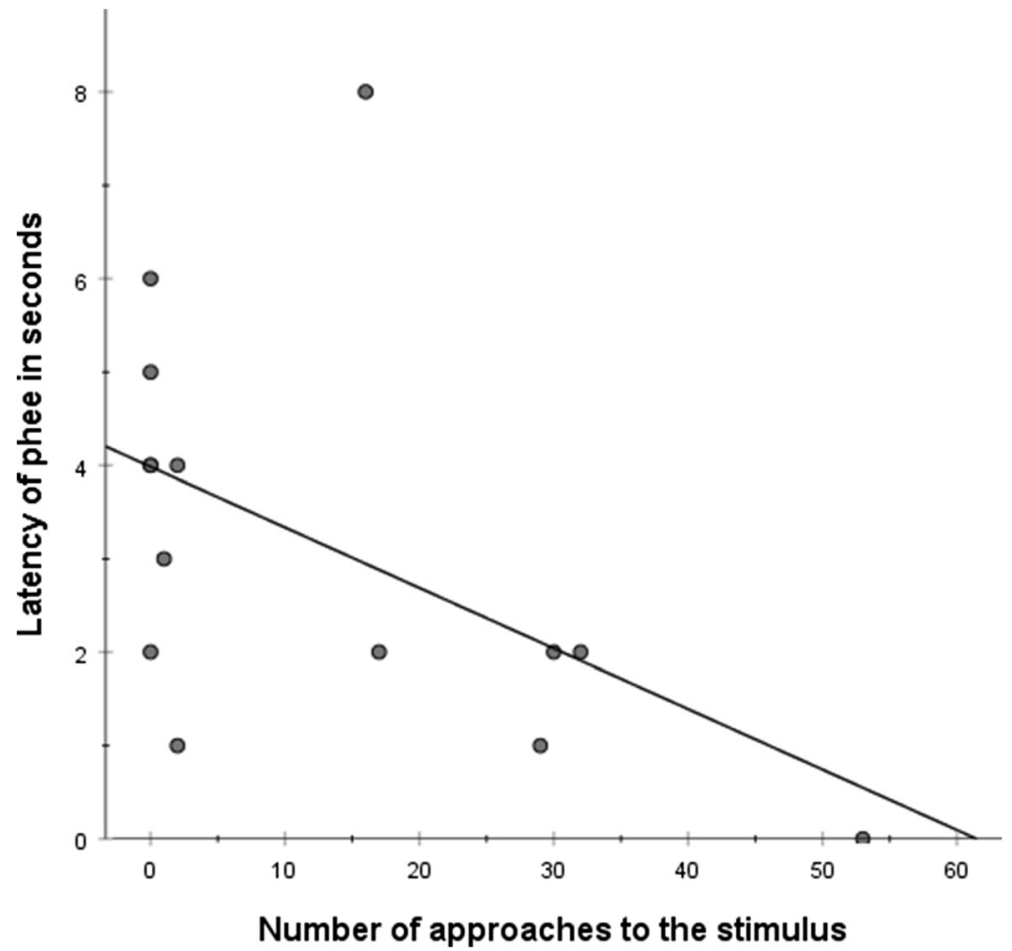

Fig. 1 Correlation between the latency to the first phee call at 15-17 days and number of approaches to a new stimulus at 3 mo for common marmosets at the Universidad Autónoma de Madrid colony, Spain, 2012-2014. 


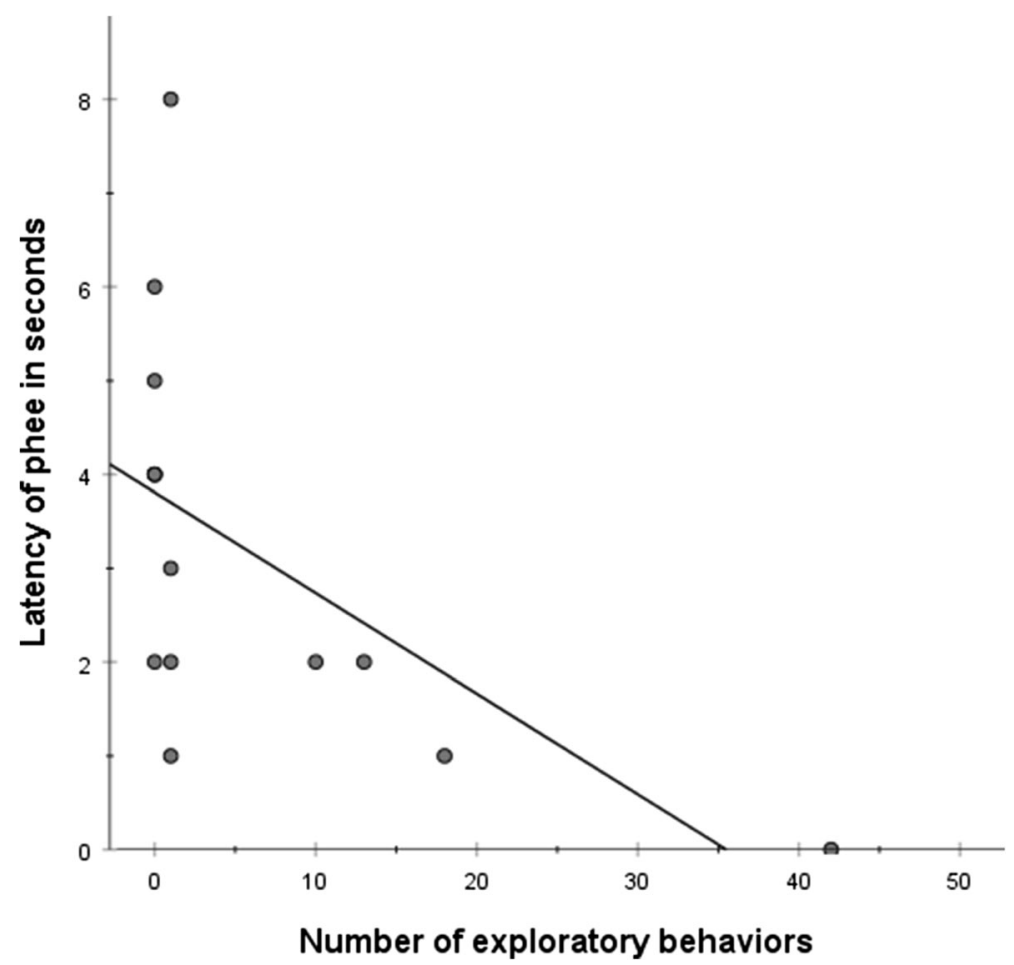

Fig. 2 Correlation between the latency to the first phee call at 15-17 days and number of exploratory behaviors to a new stimulus at 3 mo for common marmosets at the Universidad Autónoma de Madrid colony, Spain, 2012-2014.

\section{Similarities Between Twins}

Intraclass correlations for the seven pairs of twins were significant for frequency of headcocking, latency of approach, and latency of exploration (Table VII). This indicates that, for these three variables, twins were more similar to each other than to other infants in the sample.

Table V Results of Spearman's correlation tests of the relationship between the calling rate of phee in an isolation test and exploration behaviors in an exploration test for common marmosets at the Universidad Autónoma de Madrid colony, Spain (2012-2014)

\begin{tabular}{llllll}
\hline & $\begin{array}{l}\text { Frequency } \\
\text { of headccking }\end{array}$ & $\begin{array}{l}\text { Frequency } \\
\text { of approach }\end{array}$ & $\begin{array}{l}\text { Frequency } \\
\text { of exploration }\end{array}$ & $\begin{array}{l}\text { Latency of } \\
\text { approach }\end{array}$ & $\begin{array}{l}\text { Latency of } \\
\text { exploration }\end{array}$ \\
\hline$R$ & 0.154 & 0.274 & 0.191 & 0.009 & -0.127 \\
$P$ & 0.230 & 0.172 & 0.257 & 0.488 & 0.333 \\
Lower CI & -0.538 & -0.290 & -0.355 & -0.624 & -0.750 \\
Upper CI & 0.731 & 0.718 & 0.704 & 0.599 & 0.516 \\
\hline
\end{tabular}


Table VI Results of Spearman's correlation tests of the relationship between the calling rate of tsik in an isolation test and exploration behaviors in an exploration test for common marmosets at the Universidad Autónoma de Madrid colony, Spain (2012-2014)

\begin{tabular}{llllll}
\hline & $\begin{array}{l}\text { Frequency } \\
\text { of headcocking }\end{array}$ & $\begin{array}{l}\text { Frequency } \\
\text { of approach }\end{array}$ & $\begin{array}{l}\text { Frequency } \\
\text { of exploration }\end{array}$ & $\begin{array}{l}\text { Latency of } \\
\text { approach }\end{array}$ & $\begin{array}{l}\text { Latency of } \\
\text { exploration }\end{array}$ \\
\hline$R$ & -0.182 & -0.389 & -0.257 & -0.042 & 0.032 \\
$P$ & 0.267 & 0.085 & 0.186 & 0.444 & 0.457 \\
Lower CI & -0.717 & -0.810 & -0.713 & -0.633 & -0.582 \\
Upper CI & 0.426 & 0.176 & 0.305 & 0.564 & 0.656 \\
\hline
\end{tabular}

\section{Sex Differences}

We found no significant difference between the sexes for the latency of phee $(U=18, \quad P=$ $0.431)$ and tsik $(U=23, P=0.897)$ calls, or the rate of phee $(U=16, P=0.301)$ and tsik $(U=$ $21.5, P=0.746)$ calls. Similarly, there was no significant difference between the sexes for any of the exploratory behaviors: latency of approach $(U=12.5, P=0.128)$, latency of exploration $(U=10.5, P=0.74)$, frequency of approach $(U=14.5, P=0.209)$, frequency of exploration $(U=13.5, P=0.153)$, and headcocking $(U=11, P=0.85)$.

\section{Discussion}

Our results showed that the latency of phee calls during isolation at 15-17 days had a negative relationship with the frequency of approach to and exploration of a new stimulus at 3 months of age, although both correlations fall above the cut-off points for the false discovery rate. We found no other significant correlations between vocalizations and exploration behaviors. We found clear differences between groups in headcocking, latency of approach, and latency of exploration during the exploration test. In these variables, twins were more similar to each other than to other infants. However, there was no significant difference between social groups in latency and calling rate for either phee or tsik. Lastly, there were no sex differences in phee or tsik vocalizations or exploration variables.

The correlations between phee and frequency of approach and exploration suggest that marmosets that took longer to start vocalizing when isolated might also have explored less and approached the stimulus less often. However, it is important to interpret these results with caution, as both correlations fall above the cut-off points

Table VII Intraclass correlation coefficients and $P$-values for all exploration variables of the common marmosets $(n=14)$ at the Universidad Autónoma de Madrid colony, Spain (2012-2014)

\begin{tabular}{llllllll}
\hline & Frequency & & & & \multicolumn{2}{c}{ Latency } \\
\cline { 2 - 3 } & Headcocking & Approach & Exploration & & Approach & Exploration \\
\hline Intraclass correlation coefficients & 0.657 & 0.173 & -0.01 & & 0.973 & 0.75 \\
$P$ & 0.029 & 0.326 & 0.502 & & $<0.001$ & 0.011 \\
\hline
\end{tabular}


for the false discovery rate. Phee is the only long-range social call emitted by infant marmosets to contact other members of the group when they are not in sight (Bezerra and Souto 2008; Norcross and Newman 1999; Yamaguchi et al. 2010). It attracts adult attention, but it can also carry the risk of alerting nearby predators, so might function as a proactive response to isolation during early life. Infant marmosets with a more proactive style might begin vocalizing sooner when isolated at 15-17 days and explore more when a new stimulus is introduced in their cage at 3 months. These results support previous findings that indicate that coping styles show stability in behavior in macaques (Hennessy et al. 2014) and in tufted-ear marmosets (Taylor et al. 2014).

In contrast to our findings for phee calls, the latency to give tsik calls did not correlate significantly with any of the exploration or approach behaviors measured at 3 months. Tsik is considered a mobbing call (Bezerra and Souto 2008) performed in response to a threatening stimulus. During a novel stimulus test, the number of tsik calls was negatively correlated to the level of cortisol in hair samples, suggesting that this vocalization served as a coping mechanism in this situation (Clara et al. 2008). In addition to mobbing, adult marmosets produce tsik calls in several contexts associated with anxiety and fear, including isolation in unfamiliar environment (Kato et al. 2014), and infants produce tsik to signal distress (Bezerra and Souto 2008). We recorded vocalizations during an isolation context without a threatening stimulus, similar to the isolation context used to study tsik calls in adults (Kato et al. 2014). However, infants also use this vocalization to attract adult attention, as part of "tantrums" (Ventura and Buchanan-Smith 2003). Thus, calling rate and latency of tsik might reflect distress in infants (Bezerra and Souto 2008) rather than their approach to coping with the situation. Additionally, some phee and tsik calls produced by the infants were given as babbling behaviors. These spontaneous vocalizations are not used in the same ways as adult calls, but rather as part of learning to vocalize (Snowdon 2001; Snowdon and de la Torre 2002). For example, although infants often overlap their phee calls with those of adults, antiphonal calling becomes more common as it is developed through social interactions (Takahashi et al. 2016). This makes it difficult to interpret the calling rates, as some of the calls might not have been used in an adult specific way (i.e., using phee as a long-range contact call) (Snowdon 2001; Snowdon and de la Torre 2002).

We found clear social group differences in headcocking, latency of approach, and latency of exploration during the exploration test when the infants were 3 months old. Despite the possible relationship between exploration and vocalizations, there were no group differences in latency of vocalizing phee. Exploration tests performed in the group might reflect the influence of the group as well as individual differences in coping style. Our results show that twins were more similar to each other than to other infants in latency of approach, latency of exploration, and headcocking. This suggests that group differences are consistent in all infants and contrasts with findings in cottontop tamarins that indicate that exploration differences were likely due to natural variation among twins rather than group differences (Achenbach unpublished manuscript, 1999).

These group differences are congruent with previous findings that showed grouplevel similarity in exploratory behavior in marmosets (Koski and Burkart 2015; Šlipogor et al. 2016), although these differences were present only when the test was performed with the whole group, and not when tested alone (Koski and Burkart 2015). The authors hypothesize that in-group similarities in exploratory behavior facilitate 
cooperation and might be particularly adaptive for social species (Koski and Burkart 2015). More interestingly, group differences in boldness were also present even in nonsocial contexts, although the authors suggest that these differences can be explained by social effects (Koski and Burkart 2015). This presents an interesting question regarding how each individual influences the overall "group personality." For example, individuals with different social roles may have varying influence (e.g., the group personality may be similar to that of the dominant pair). More data are needed in regard to how individuals change their behaviors in the presence of other group members to better understand how social structure might influence exploration style.

While these findings are interesting, it is important to consider the methodological approach used and its limitations. Studies of coping styles in common marmosets have shown that exploration tests are an effective experimental condition that elicits individual differences in behavior (Clara et al. 2008; Koski and Burkart 2015), both in isolation and in the group. However, exploration tests are not appropriate in infants younger than 8 weeks, at which point infants start to move more independently from their carriers (Tardif et al. 2003). We combined an isolation test, to elicit contact calls in a stress inducing context, with an exploration test, to elicit explorative behavior. While both the isolation test and the exploration test elicited individual differences in marmosets, an alternative interpretation is that the behaviors measured are not evidence of the same coping style but are different but closely related coping mechanisms (coping with isolation vs. exploration).

In summary, coping style in marmosets may be stable from as early as 15 days after birth. Marmosets that gave long range contact calls sooner at 15-17 days also showed more exploratory behaviors at 3 months. We also found group differences in exploration, supporting the findings of previous studies (Koski and Burkart 2015; Šlipogor et al. 2016) and suggesting that marmosets might adapt their behavior to act in accordance to the group, although there are clear similarities between twins. Our findings open new interesting questions for future research, including the possible influence of individuals on "group personality," and the possible use of latency to phee call in isolation as an indication of coping style.

Acknowledgements This project received funding from a grant from the Spanish Ministerio de Economía y Competitividad, "Proyectos de Investigación Fundamental No Orientada Ministerio de Economía y Competitividad," PSI 2012-30744. We would like to thank Esther Aguilera and Sara Palhão Farinha da Silva for their help and contributions during the exploration test. We would also like to thank two anonymous reviewers and the editor for their comments and recommendations on the original manuscript.

Authors' Contributions SD, SS and AF conceived the study and contributed to the data collection. SD analyzed the data and wrote the manuscript. SS and AF devised the methodology and provided editorial advice.

Open Access This article is licensed under a Creative Commons Attribution 4.0 International License, which permits use, sharing, adaptation, distribution and reproduction in any medium or format, as long as you give appropriate credit to the original author(s) and the source, provide a link to the Creative Commons licence, and indicate if changes were made. The images or other third party material in this article are included in the article's Creative Commons licence, unless indicated otherwise in a credit line to the material. If material is not included in the article's Creative Commons licence and your intended use is not permitted by statutory regulation or exceeds the permitted use, you will need to obtain permission directly from the copyright holder. To view a copy of this licence, visit http://creativecommons.org/licenses/by/4.0/. 


\section{References}

Agamaite, J. A., Chang, C.-J., Osmanski, M. S., \& Wang, X. (2015). A quantitative acoustic analysis of the vocal repertoire of the common marmoset (Callithrix jacchus). The Journal of the Acoustical Society of America, 138(5), 2906. https://doi.org/10.1121/1.4934268.

Bezerra, B. M., \& Souto, A. (2008). Structure and usage of the vocal repertoire of Callithrix jacchus. International Journal of Primatology, 29(3), 671-701.

Carere, C., \& Locurto, C. (2011). Interaction between animal personality and animal cognition. Current Zoology, 57(4), 491-498.

Carere, C., Caramaschi, D., \& Fawcett, T. W. (2010). Covariation between personalities and individual differences in coping with stress: Converging evidence and hypotheses. Current Zoology, 56(6), 728-740.

Clara, E., Tommasi, L., \& Rogers, L. J. (2008). Social mobbing calls in common marmosets (Callithrix jacchus): Effects of experience and associated cortisol levels. Animal Cognition, 11(2), 349-358.

Clarke, A. S., \& Boinski, S. (1995). Temperament in nonhuman primates. American Journal of Primatology, 37(2), 103-125. https://doi.org/10.1002/ajp.1350370205.

Cronin, K. A., van Leeuwen, E. J. C., Vreeman, V., \& Haun, D. B. M. (2014). Population-level variability in the social climates of four chimpanzee societies. Evolution and Human Behavior, 35(5), 389-396. https://doi.org/10.1016/j.evolhumbehav.2014.05.004.

Cross, N., \& Rogers, L. J. (2006). Mobbing vocalizations as a coping response in the common marmoset. Hormones and Behavior, 49(2), 237-245.

de Arruda, M. F., Yamamoto, M. E., \& Bueno, O. F. A. (1986). Interactions between parents and infants, and infants-father separation in the common marmoset (Callithrix jacchus). Primates, 27(2), 215-228.

Drent, P. J., van Oers, K., \& van Noordwijk, A. J. (2003). Realized heritability of personalities in the great tit (Parus major). Proceedings of the Royal Society of London B: Biological Sciences, 270(1510), 45-51.

Ferreira, R. G., Mendl, M., Wagner, P. G. C., Araujo, T., Nunes, D., \& Mafra, A. L. (2016). Coping strategies in captive capuchin monkeys (Sapajus spp.). Applied Animal Behaviour Science, 176, 120-127. https://doi.org/10.1016/J.APPLANIM.2015.12.007.

Garber, P. A., Porter, L. M., Spross, J., \& Di Fiore, A. (2016). Tamarins: Insights into monogamous and nonmonogamous single female social and breeding systems. American Journal of Primatology, 78(3), 298314. https://doi.org/10.1002/ajp.22370.

García, L. V. (2003). Controlling the false discovery rate in ecological research. Trends in Ecology \& Evolution, 18(11), 553-554. https://doi.org/10.1016/j.tree.2003.08.008.

Gosling, S. D. (2001). From mice to men: What can we learn about personality from animal research? Psychological Bulletin, 127(1), 45-86.

Gosling, S. D. (2008). Personality in non-human animals. Social and Personality Psychology Compass, 2(2), 985-1001.

Gosling, S. D., \& John, O. P. (1999). Personality dimensions in nonhuman animals. Current Directions in Psychological Science, 8(3), 69-75.

Hennessy, M. B., McCowan, B., Jiang, J., \& Capitanio, J. P. (2014). Depressive-like behavioral response of adult male rhesus monkeys during routine animal husbandry procedure. Frontiers in Behavioral Neuroscience, 8, 1-8. https://doi.org/10.3389/fnbeh.2014.00309.

Iwanicki, S., \& Lehmann, J. (2015). Behavioral and trait rating assessments of personality in common marmosets (Callithrix jacchus). Journal of Comparative Psychology, 129(3), 205-217.

Kaplan, G., \& Rogers, L. J. (2006). Head-cocking as a form of exploration in the common marmoset and its development. Developmental Psychobiology, 48(7), 551-560. https://doi.org/10.1002/dev.20155.

Kato, Y., Gokan, H., Oh-Nishi, A., Suhara, T., Watanabe, S., \& Minamimoto, T. (2014). Vocalizations associated with anxiety and fear in the common marmoset (Callithrix jacchus). Behavioural Brain Research, 275, 43-52. https://doi.org/10.1016/J.BBR.2014.08.047.

Koolhaas, J. M., Korte, S. M., De Boer, S. F., Van Der Vegt, B. J., Van Reenen, C. G., et al (1999). Coping styles in animals: Current status in behavior and stress-physiology. Neuroscience \& Biobehavioral Reviews, 23(7), 925-935.

Koolhaas, J. M., De Boer, S. F., Coppens, C. M., \& Buwalda, B. (2010). Neuroendocrinology of coping styles: Towards understanding the biology of individual variation. Frontiers in Neuroendocrinology, 31(3), 307-321.

Koski, S. E. (2011). Social personality traits in chimpanzees: Temporal stability and structure of behaviourally assessed personality traits in three captive populations. Behavioral Ecology and Sociobiology, 65(11), 2161-2174. https://doi.org/10.1007/s00265-011-1224-0.

Koski, S. E., \& Burkart, J. M. (2015). Common marmosets show social plasticity and group-level similarity in personality. Scientific Reports, 5(1), 8878. https://doi.org/10.1038/srep08878. 
Koski, S. E., Buchanan-Smith, H. M., Ash, H., Burkart, J. M., Bugnyar, T., \& Weiss, A. (2017). Common marmoset (Callithrix jacchus) personality. Journal of Comparative Psychology, 131(4), 326-336. https://doi.org/10.1037/com0000089.

Linden, J. B., Capitanio, J. P., McCowan, B., \& Isbell, L. A. (2018). Coping style and cortisol levels in infancy predict hair cortisol following new group formation in captive rhesus macaques (Macaca mulatta). American Journal of Primatology, 80(12), e22938. https://doi.org/10.1002/ajp.22938.

McDonald, J. H. (2014). Handbook of biological statistics, 3rd ed. Retrieved from: http://www. biostathandbook.com/multiplecomparisons.html

McGraw, K. O., \& Wong, S. P. (1996). Forming inferences about some intraclass correlation coefficients. Psychological Methods, 1(1), 30-46. https://doi.org/10.1037/1082-989X.1.1.30.

Miller, C. T., Mandel, K., \& Wang, X. (2010). The communicative content of the common marmoset phee call during antiphonal calling. American Journal of Primatology, 72(11), 974-980. https://doi.org/10.1002 /ajp.20854.

Nakagawa, S. (2004). A farewell to Bonferroni: The problems of low statistical power and publication bias. Behavioral Ecology, 15(6), 1044-1045. https://doi.org/10.1093/beheco/arh107.

Norcross, J. L., \& Newman, J. D. (1999). Effects of separation and novelty on distress vocalizations and cortisol in the common marmoset (Callithrix jacchus). American Journal of Primatology, 47(3), 209-222.

Pistorio, A. L., Vintch, B., \& Wang, X. (2006). Acoustic analysis of vocal development in a New World primate, the common marmoset (Callithrix jacchus). The Journal of the Acoustical Society of America, 120(3), 1655-1670. https://doi.org/10.1121/1.2225899.

Saito, A. (2015). The marmoset as a model for the study of primate parental behavior. Neuroscience Research, 93, 99-109. https://doi.org/10.1016/J.NEURES.2014.12.011.

Sánchez, S., Peláez, F., Morcillo, A., \& Gil-Burmann, C. (2005). Effect the enclosure on carriers' body weight loss in the cotton-top tamarin (Saguinus oedipus). American Journal of Primatology, 66, 279-284.

Sánchez, S. M., Ziegler, T. E., \& Snowdon, C. T. (2014). Both parents respond equally to infant cues in the cooperatively breeding common marmoset, Callithrix jacchus. Animal Behaviour, 97, 95-103. https://doi. org/10.1016/j.anbehav.2014.09.002.

Schiel, N., \& Souto, A. (2017). The common marmoset: An overview of its natural history, ecology and behavior. Developmental Neurobiology, 77(3), 244-262. https://doi.org/10.1002/dneu.22458.

Sih, A., Bell, A., Chadwick Johnson, J., \& Ziemba, R. E. (2004). Behavioral syndromes: An integrative overview. The Quarterly Review of Biology, 79(3), 241-277. https://doi.org/10.1086/422893.

Šlipogor, V., Gunhold-de Oliveira, T., Tadić, Z., Massen, J. J. M., \& Bugnyar, T. (2016). Consistent inter-individual differences in common marmosets (Callithrix jacchus) in Boldness-Shyness, Stress-Activity, and ExplorationAvoidance. American Journal of Primatology, 78(9), 961-973. https://doi.org/10.1002/ajp.22566.

Snowdon, C. T. (2001). Social processes in communication and cognition in callitrichid monkeys: A review. Animal Cognition, 4, 247-257. https://doi.org/10.1007/s100710100094.

Snowdon, C. T., \& De La Torre, S. (2002). Multiple environmental contexts and communication in pygmy marmosets (Cebuella pygmaea). Journal of Comparative Psychology, 116(2), 182-188. https://doi. org/10.1037/0735-7036.116.2.182.

Suomi, S. J. (1997). Early determinants of behaviour: Evidence from primate studies. British Medical Bulletin, 53(1), 170-184.

Takahashi, D. Y., Fenley, A. R., \& Ghazanfar, A. A. (2016). Early development of turn-taking with parents shapes vocal acoustics in infant marmoset monkeys. Philosophical Transactions of the Royal Society B: Biological Sciences, 371(1693), 20150370. https://doi.org/10.1098/rstb.2015.0370.

Tardif, S. D., Smucny, D. A., Abbott, D. H., Mansfield, K., Schultz-Darken, N., \& Yamamoto, M. E. (2003). Reproduction in captive common marmosets (Callithrix jacchus). Comparative Medicine, 53(4), 364-368 Retrieved from https://www.ingentaconnect.com/content/aalas/cm/2003/00000053/00000004/art00005.

Taylor, J. H., Mustoe, A. C., \& French, J. A. (2014). Behavioral responses to social separation stressor change across development and are dynamically related to HPA activity in marmosets. American Journal of Primatology, 76(3), 239-248. https://doi.org/10.1002/ajp.22228.

Ventura, R., \& Buchanan-Smith, H. M. (2003). Physical environmental effects on infant care and development in captive Callithrix jacchus. International Journal of Primatology, 24(2), 399-413.

Yamaguchi, C., Izumi, A., \& Nakamura, K. (2010). Time course of vocal modulation during isolation in common marmosets (Callithrix jacchus). American Journal of Primatology, 72(8), 681-688. https://doi. org/10.1002/ajp.20824.

Zahed, S. R., Prudom, S. L., Snowdon, C. T., \& Ziegler, T. E. (2008). Male parenting and response to infant stimuli in the common marmoset (Callithrix jacchus). American Journal of Primatology, 70(1), 84-92. https://doi.org/10.1002/ajp.20. 